\title{
Correspondence
}

\section{Screening for sickle cell disease in children with cleft lip and palate}

To the Editor:

We read with interest Crawford and co-workers' study ${ }^{1}$ describing the effectiveness of preoperative screening of children for sickle cell disease (SCD) in an ethnic group (children of African ancestry). In this part of rural and tribal central India, SCD is highly prevalent in certain tribal and ethnic groups. ${ }^{2}$ In regions such as ours where patients have limited access to medical facilities, the perioperative period may actually be a useful time to screen for SCD. Crawford et al. refer to the lack of follow-up and parental counselling as disadvantages of routine perioperative testing. This may be overcome by preoperative efforts to evaluate, investigate, and treat and/or follow-up patients with anemia by pediatricians or perioperative physicians.

In children presenting for cleft surgery, using anemia as a criterion to screen for SCD is confounded by nutritional anemia. In children with cleft lips and palates, anemia and failure to thrive (FTT) are well known complications of deficient dietary intake. ${ }^{3}$ Our experience suggests that both anemia and FTT occur concomitantly, and that the most severely affected children are in the pre-school years. Therefore, in children with cleft lips and palates, we screen for SCD when there is a disparity between the severity of anemia and FTT (e.g., anemia with no FTT) or when there is unexplained anemia in older age groups. Additionally we screen these children for SCD if there is severe anemia (hemoglobin $<5 \mathrm{~g} \cdot \mathrm{dL}^{-1}$ ), past symptoms, clinical features or family history of $\mathrm{SCD},{ }^{4}$ or if patients belong to the above-mentioned indigenous populations. ${ }^{5}$

We agree with Crawford et al.'s statement that the risk of a well-conducted general anesthetic in the asymptomatic child with undiagnosed sickle cell disease is probably low, especially when factors that precipitate erythrocyte sickling are avoided (anemia, acidosis, dehydration, hypoxia, hypercarbia, hypothermia and stress responses). We further note that these authors state that perioperative sickle-related complications occurred only in patients who had a longstanding history of sickle cell disease, and who were undergoing surgery (cholecystectomy or splenectomy) for related complications.
Despite these reassurances, further studies are required to determine the effectiveness of preoperative screening for SCD in our part of the world (with SCD in certain populations) and especially in children with a high incidence of nutritional anemia (with cleft lips and palates).

Naveen Eipe MD

Manish Alexander MD

Ruma Alexander MD

Padhar Hospital, Padhar, India

E-mail: neipe@yahoo.com

Accepted for publication February 28, 2006.

\section{References}

1 Crawford MW, Galton S, Abdelhaleem M. Preoperative screening for sickle cell disease in children: clinical implications. Can J Anesth 2005; 52: 1058-63.

2 Patel AB, Athavale AM. Sickle cell disease in central India. Indian J Pediatr 2004; 71: 789-93.

3 Pandya AN, Boorman JG. Failure to thrive in babies with cleft lip and palate. Br J Plast Surg 2001; 54: $471-5$.

4 Quiorolo K, Vichinsky E. Hemoglobin disorders. In: Behrman RE, Kliegman RM, Jenson HB (Eds). Nelson Textbook of Pediatrics, $17^{\text {th }}$ ed. Philadelphia: Elsevier 2004; 454: 1623-34.

5 Gupta RB, Tiwary RS, Pande PL, et al. Hemoglobinopathies among the Gond tribal groups of central India; interaction of alpha- and beta-thalassemia with beta chain variants. Hemoglobin 1991; 15: 441-58.

Reply:

We would like to thank Dr. Eipe et al. for their interest and comments on our article on preoperative screening for sickle cell disease. As they correctly point out, in areas where access to medical facilities is limited and sickle cell disease is prevalent, the preoperative period may be a useful time to screen for this hemoglobinopathy. This may be helpful for long-term health care and counselling, but the benefit of such screening with regard to perioperative outcome has yet to be established. For the reasons cited in our study, ${ }^{1}$ the potential benefit of universal preoperative screening in terms of perioperative outcome is questionable in our population. We agree with Dr. Eipe 